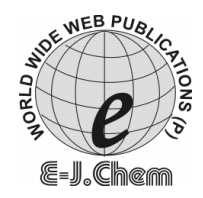

http://www.e-journals.net
ISSN: 0973-4945; CODEN ECJHAO

E-Journal of Chemistry

2009, 6(2), 541-544

\title{
Simultaneous Determination of Simvastatin and Ezetimibe in Tablets by HPLC
}

\author{
D. ANANTHA KUMAR, D. P. SUJAN, \\ V. VIJAYASREE and J. V. L. N. SESHAGIRI RAO* \\ A.U. College of Pharmaceutical Sciences, \\ Andhra University, Visakhapatnam-530003, India. \\ jvlns@yahoo.com
}

Received 23 October 2008; Accepted 12 December 2008

\begin{abstract}
A reverse phase high performance liquid chromatographic method was developed for the simultaneous determination of simvastatin and ezetimibe in tablet dosage forms. The separation was effected on a C18 Supelcosil column $(250 \mathrm{~mm} \times 4.6 \mathrm{~mm} ; 5 \mu)$ using a mobile phase consisting of $0.01 \mathrm{M}$ ammonium acetate buffer and acetonitrile $(35: 65 \mathrm{v} / \mathrm{v})$ at a flow rate of $1 \mathrm{~mL} / \mathrm{min}$. The detection was made at $240 \mathrm{~nm}$. The retention times for ezetimibe and simvastatin were 5.9 and $8.5 \mathrm{~min}$ respectively. Calibration curves were linear over the ranges of $0.5-40 \mu \mathrm{g} / \mathrm{mL}$ for simvastatin and $2.5-50 \mu \mathrm{g} / \mathrm{mL}$ for ezetimibe. The proposed method was validated as per the ICH and USP guidelines. The method is accurate and precise and found to be suitable for the quantitative analysis of both the drugs individually and in combination in tablet dosage forms.
\end{abstract}

Keywords: Simvastatin, Ezetimibe, Determination, HPLC

\section{Introduction}

Simvastatin, a methylated analog of lovastatin, is the lactone form of 1', 2', 6', 7', 8', 8' hexahydro-3, 5, -dihydroxy- 2, 6'-dimethyl- 8'(2", 2" - dimethyl -1" oxo - butoxy) 1' naphthalene heptanoic acid. This drug, which acts by inhibiting 3-hydroxy-3 methyl glutarylcoA reductase is used in the treatment of hypercholesterolaemia ${ }^{1}$. Ezetemibe (1-(4flurophenyl)-3(R)-[3(S)-(4-flurophenyl) -3-hydroxy propyl] -4(S) (4 - hydroxyphenyl) azetidin- 2- one), which belongs to a group of selective and very effective 2-azetidione cholesterol absorption inhibitors acts at the level of cholesterol entry into enterocytes ${ }^{2}$. Clinical studies have shown that co-administration of ezetimibe with statins could provide an additional reduction in LDL cholesterol as well as total cholesterol ${ }^{3}$. A few methods based on HPLC ${ }^{4-6}$, $\mathrm{UV}^{7}, \mathrm{LC}^{-\mathrm{MS}^{8,9}}$ and GC-MS ${ }^{10}$ were reported earlier for the determination of simvastatin 
individually and in combination with other drugs. A few analytical procedures were also proposed for the determination of ezetimibe in dosage forms ${ }^{11}$ in human serum, urine and feces $^{12}$. This paper now describes an RP-HPLC method for the simultaneous determination of simvastatin and ezetimibe in tablets. The method is rapid, accurate and precise.

\section{Experimental}

\section{Chromatographic conditions}

A Jasco HPLC system equipped with a supelcosil C18 column (250 mm x $4.6 \mathrm{~mm}$; $5 \mu)$, a pump (PU 2080), a sample injector (Rheodyne 7125) with a $20 \mu \mathrm{l}$ loop and a UV detector (UV-2075) connected to a model 720 Data Module integrator was employed for the analysis.

A mobile phase consisting of a mixture of $0.01 \mathrm{M}$ ammonium acetate buffer ( $\mathrm{pH}$ 6.8) and acetonitrile in the ratio of 35:65 v/v was prepared, filtered through a $0.45 \mu \mathrm{m}$ membrane filter and degassed prior to use. All the reagents used were of analytical grade. Acetonitrile of HPLC grade (Merck), ammonium acetate (Aldrich) and water purified by Milli-Q system (Millipore) were used for the preparation of the mobile phase.

\section{Drug samples}

Working standard samples of simvastatin and ezetimibe used in this study were gifted by Aurobindo Pharma Ltd., Hyderabad and Dr. Reddy's Laboratories Ltd., Hyderabad respectively. A commercial sample of tablets of simvas-ez of Micro Laborataories, Bangalore containing $10 \mathrm{mg}$ each of simvastatin and ezetimibe was used in the study.

\section{Preparation of drug solutions}

Primary stock solutions of simvastatin $(100 \mu \mathrm{g} / \mathrm{mL})$ and ezetimibe $(100 \mu \mathrm{g} / \mathrm{mL})$ were prepared separately by dissolving them in the mobile phase. These solutions were further diluted to obtain the working standard solutions in the concentration range of $0.5-40 \mu \mathrm{g} / \mathrm{mL}$ for simvastatin and $2.5-50 \mu \mathrm{g} / \mathrm{mL}$ for ezetimibe. The working standard solutions of both the drugs were prepared individually as well as in combination. Twenty microlitres of this solution was injected each time into the column at a flow rate of $1 \mathrm{~mL} / \mathrm{min}$. The detection of the method was monitored at $240 \mathrm{~nm}$. Each of the dilutions was injected for five times into the column and the corresponding chromatograms were obtained. The retention times for ezetimibe and simvastatin were found to be $5.9 \mathrm{~min}$ and $8.5 \mathrm{~min}$ respectively. Graphs were plotted between the mean peak areas of the drugs with respect to concentration. The curves were found to be linear in the concentration range of $0.5-40 \mu \mathrm{g} / \mathrm{mL}$ for simvastatin and $2.5-50 \mu \mathrm{g} / \mathrm{mL}$ for ezetimibe.

For testing the suitability of the proposed method for the estimation of the drugs in dosage form, ten tablets each containing $10 \mathrm{mg}$ each of simvastatin and ezetimibe were taken and powdered. A quantity of the powder equivalent to $50 \mathrm{mg}$ of each of the drug was transferred to a $50 \mathrm{~mL}$ volumetric flask and placed in an ultrasonic bath at room temperature for $15 \mathrm{~min}$. The contents of the flask were made up to volume with acetonitrile and filtered through a $0.45 \mu$ membrane filter. The filtrate was suitably diluted with the mobile phase in order to obtain test solutions in the concentration range of 2.5 to $50 \mu \mathrm{g} / \mathrm{mL}$ for ezetimibe and 0.5 to $40 \mu \mathrm{g} / \mathrm{mL}$ for simvastatin.. Each of these solutions $(20 \mu \mathrm{L})$ was then injected into the column. The mean peak areas of ezetimibe and simvastatin in the sample solution were found out from five such determinations and drug content in the tablets was quantified using the regression equation obtained for the pure drug samples. A typical chromatogram obtained for a tablet sample solution is shown in Figure 1. 


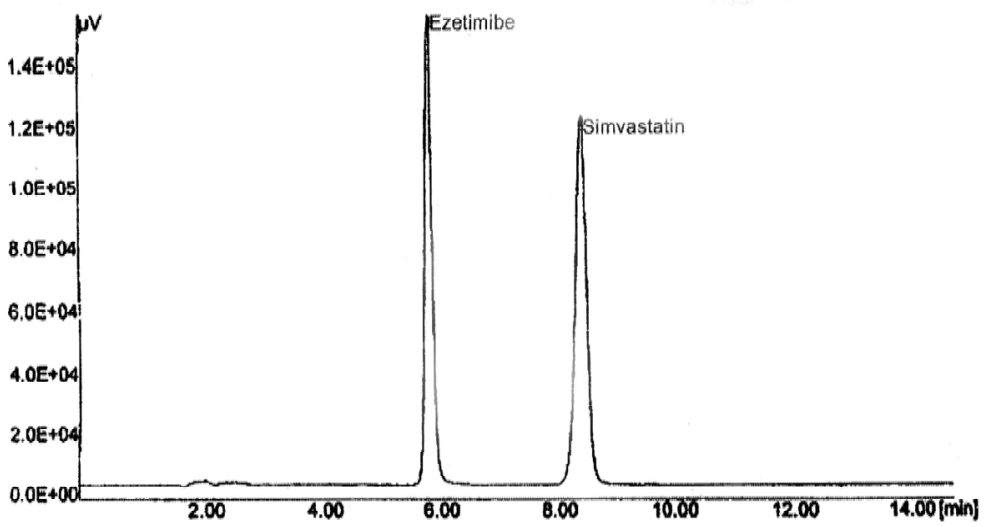

Figure 1. Typical chromatogram for the estimation of simvastain and ezetimibe.

\section{Method validation}

The developed analytical method was validated as per the guidelines of USP and ICH for the parameters like specificity, linearity, precision, accuracy, limit of detection and limit of quantification. To evaluate the linearity of the analytical method, five dilutions were made from the standard stock solutions in the working range of $0.5-40 \mu \mathrm{g} / \mathrm{mL}$ for simvastatin and $2.5-50$ $\mu \mathrm{g} / \mathrm{mL}$ for ezetimibe respectively. Accuracy was determined by applying the proposed method to the laboratory made solutions containing $2.5,5.0$ and $10.0 \mu \mathrm{g} / \mathrm{mL}$ of each drug and the corresponding percent RSD values are shown in Table 1. Precision of the analytical method was studied in terms of repeatability (intra-day) and intermediate precision (inter-day). Repeatability was checked by analysing three independent samples of both the drugs at 100 percent concentration levels and percent relative standard deviation (\% RSD) was calculated. To determine intermediate precision, mixed solutions of simvastatin and ezetimibe at three different concentration levels were analysed three times within the sameday (intra-day) and on three different days (inter-day variation). The results are shown in Table 2. Mean recoveries for simvastatin and ezetimibe from formulations were calculated and the results are shown in Table 3.

Table 1. Accuracy data for the HPLC assay of simvastatin and ezetemibe.

\begin{tabular}{ccccc}
\hline Analyte & Amount taken, $\mu \mathrm{g}$ & Amount found \pm s.d & \%Recovery & \% RSD \\
\hline Simvastatin & 2.5 & $2.49 \pm 0.022$ & 99.60 & 0.88 \\
& 5.0 & $4.98 \pm 0.041$ & 99.66 & 0.82 \\
Ezetimibe & 10.0 & $10.01 \pm 0.036$ & 100.16 & 0.35 \\
& 2.5 & $2.52 \pm 0.038$ & 100.8 & 0.15 \\
& 5.0 & $5.03 \pm 0.033$ & 100.6 & 0.65 \\
& 10.0 & $9.94 \pm 0.026$ & 99.4 & 0.26 \\
\hline
\end{tabular}

Table 2. Inter-day and Intra-day assay of the proposed method.

\begin{tabular}{|c|c|c|c|c|}
\hline \multirow{3}{*}{$\begin{array}{l}\text { Concentration of } \\
\text { drug, } \mu \mathrm{g} / \mathrm{mL}\end{array}$} & \multicolumn{4}{|c|}{ Precision data } \\
\hline & \multicolumn{2}{|c|}{$\begin{array}{c}\text { Intra-day precision } \\
\% \mathrm{RSD}\end{array}$} & \multicolumn{2}{|c|}{$\begin{array}{c}\text { Inter-day precision } \\
\% \text { RSD }\end{array}$} \\
\hline & Simvastain & Ezetimibe & Simvastatin & Ezetimibe \\
\hline 10 & 0.42 & 0.07 & 0.55 & 0.66 \\
\hline 20 & 0.69 & 0.17 & 0.49 & 0.91 \\
\hline 30 & 0.53 & 0.58 & 0.93 & 0.45 \\
\hline
\end{tabular}


Table 3. HPLC analysis of tablets formulations

\begin{tabular}{cccc}
\hline Commercial sample & amount taken, mg & Amount found, mg, \pm s.d., $\mathrm{n}=5$ & $\%$ RSD \\
\hline Simvastatin & 10 & $9.97 \pm 0.043$ & 0.43 \\
Ezetimibe & 10 & $10.05 \pm 0.072$ & 0.71 \\
\hline
\end{tabular}

\section{Results and Discussion}

The present study was undertaken to develop a sensitive, precise and accurate HPLC method for the simultaneous estimation of ezetimibe and simvastatin in pharmaceutical dosage forms. The peak shape and resolution were found to be good when the mobile phase comprising of the buffer and acetonitrile was used in the ratio of 35:65 $(\mathrm{v} / \mathrm{v})$ at a flow rate of $1 \mathrm{~mL} / \mathrm{min}$.

The standard curve was obtained in the range of $0.5-40 \mu \mathrm{g} / \mathrm{mL}$ for simvastatin with a goodness-of-fit of $\left(\mathrm{r}^{2}\right) 0.9998$ and $2.5-50 \mu \mathrm{g} / \mathrm{mL}$ for ezetimibe with a goodness-of-fit of 0.9997 . Thus, it is evident that the method is accurate within the desired range. The analytical method passed the tests for repeatability and intermediate precision for both drugs. The within day percent RSD values and intermediate RSD values obntained for simvastatin and ezetimibe are within the acceptable limits of $<2 \%$. These results are shown in Table 3. Mean recovery values for simvastatin and ezetimibe (Table 4) reveal that the method is accurate. The LOD and LOQ for simvastatin were found to be $0.5 \mu \mathrm{g} / \mathrm{mL}$ and $0.1 \mu \mathrm{g} / \mathrm{mL}$ respectively while for ezetimibe the corresponding values were 1.0 and $0.3 \mu \mathrm{g} / \mathrm{mL}$ respectively. The system suitability parameters like column efficiency $(\mathrm{N})$, resolution $\left(\mathrm{R}_{\mathrm{s}}\right)$, capacity factor $\left(\mathrm{k}^{\prime}\right)$, selectivity factor $(\alpha)$ and peak asymmetry factor $\left(\mathrm{A}_{\mathrm{s}}\right)$ were calculated as per USP guidelines and are presented in Table 4.

Table 4. System suitability data for $10 \mu \mathrm{g} / \mathrm{ml}$ of mixed standard solution.

\section{Conclusion}

\begin{tabular}{lccccc}
\hline & $\mathrm{R}_{\mathrm{S}}$ & $\mathrm{N}$ & $\mathrm{k}$ & $\alpha$ & $\mathrm{A}_{\mathrm{S}}$ \\
\hline Ezetimibe & --- & 4689 & 2.08 & ---- & 1.18 \\
Simvastatin & 9.97 & 9154 & 4.78 & 2.27 & 1.29 \\
\hline
\end{tabular}

The proposed LC chromatographic method is rapid, accurate and precise for the simultaneous detetmination of simvastatin and ezetimibe in tablet dosage forms and can be used for routine quality control of these drugs in formulations.

\section{Acknowledgements}

The authors are thankful to Aurobindo Phama Ltd., Hyderabad and Dr.Reddy's Pharmaceuticals Ltd., for providing working standard samples of simvastatin and ezetimibe respectively.

\section{References}

1. Vanheek M, France C F and Compton D S, Pharmacol Exp Ther., 1997, 283, 157.

2. Lipka L, Kerzner B and Corbelli J, Am J Cardiol., 2003, 91, 418.

3. Melani L, Mills R and Hassman D, Eur Heart J., 2003, 24, 717.

4. Vuletic M, Cindric M and Kouznjak J D, J Pharm Biomed Anal., 2005, 37, 715.

5. Carlucci G, and Mazzeo P, J Pharm Biomed Anal., 1992, 10, 693.

6. Ochiai H, Chiyama N K and Imagaki S, J Chromatogr B, 1997, 694, 211.

7. Wang L and Asgharnejad M, J Pharm Biomed Anal., 2000, 21, 1243.

8. Srinivasu M K, Narasaraju A and Omreddy G, J Pharm Biomed Anal., 2002, 29, 715.

9. Yang H, Feng Y and Luan Y, J Chromatogr B, 2003, 785, 369.

10. Tokano T, and Abe S, Biomed Environ Mass Spectrom., 1990, 19, 577.

11. Sistla R, Tata V S S K and Diwan P V, J Pharm Biomed Anal., 2005, 39, 517.

12. Oswald S, Scheuch E, Cascorbid I. and Siegmund W, J Chromatogr B , 2006, 830, 143-150. 


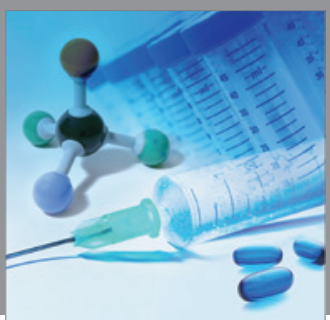

International Journal of

Medicinal Chemistry

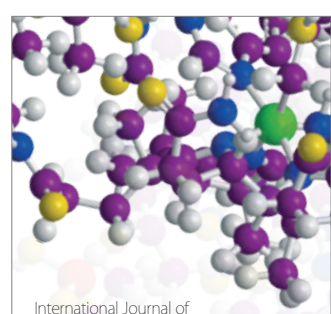

Carbohydrate Chemistry

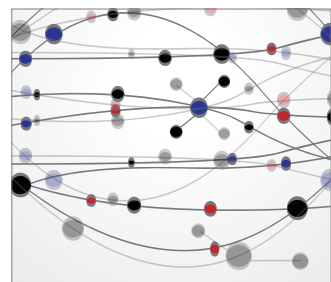

The Scientific World Journal
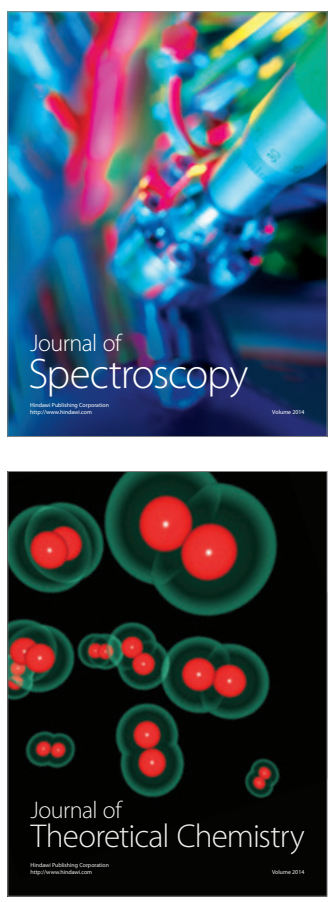
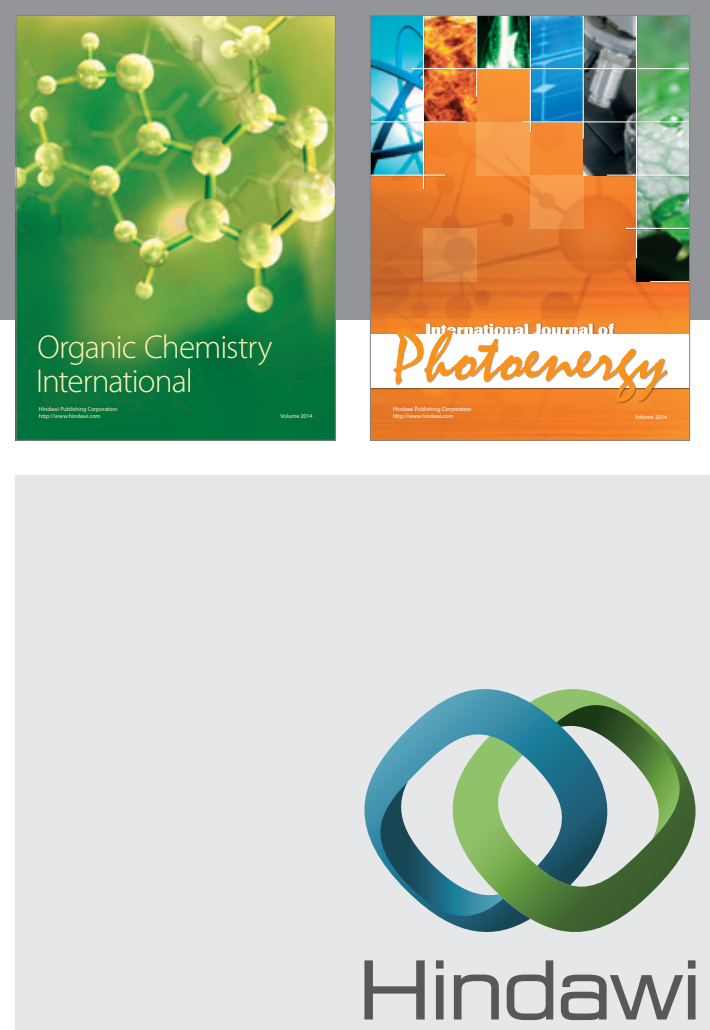

Submit your manuscripts at

http://www.hindawi.com
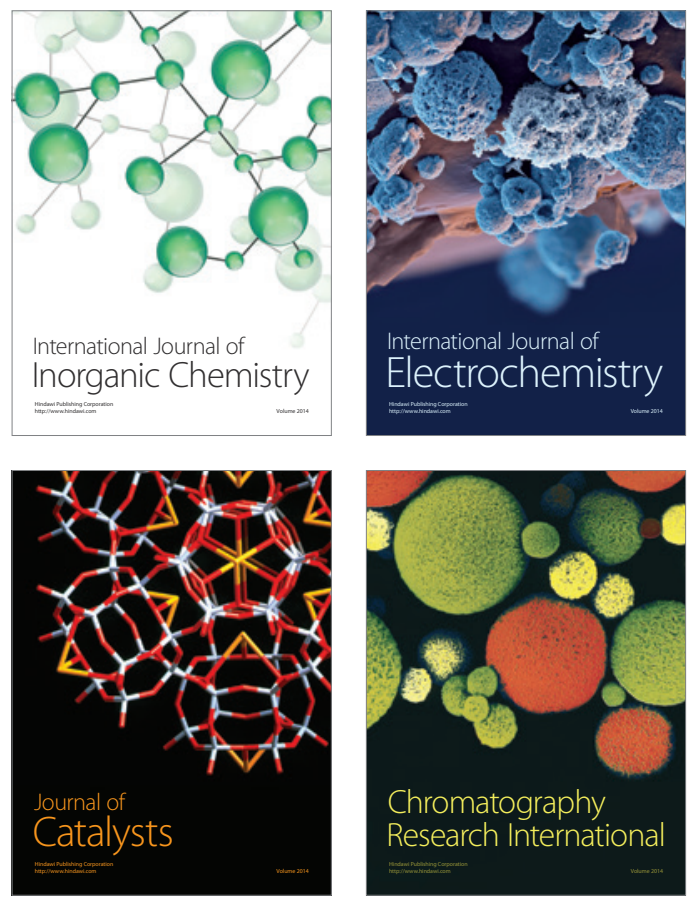
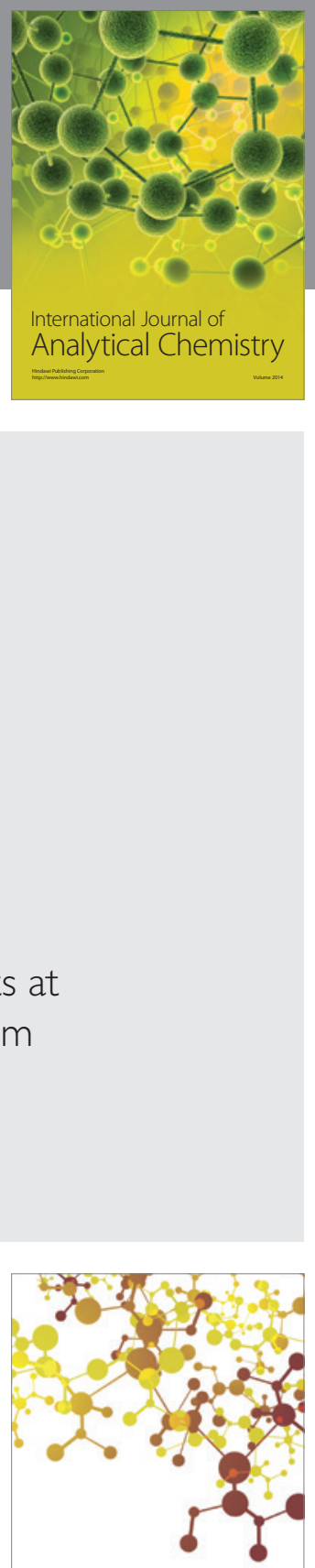

Journal of

Applied Chemistry
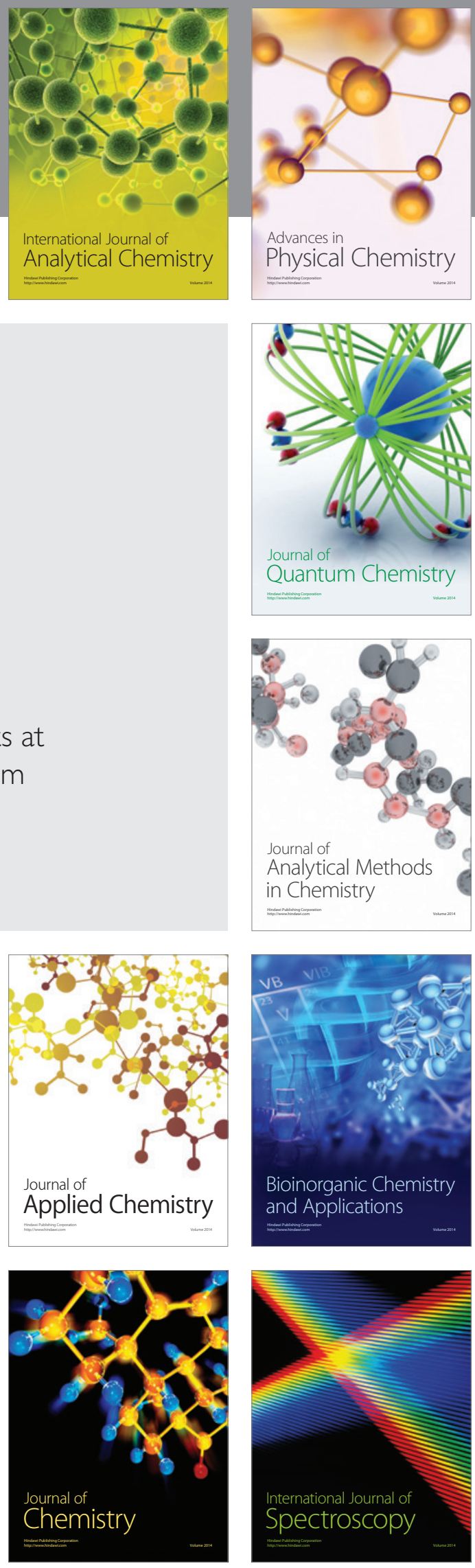